\title{
CONSTRUCTION OF A ROTOR RADIAL VIBRATION MODEL OF EMU ELECTROMECHANICAL ENERGY CONVERSION EQUIPMENT USING THE FINITE ELEMENT METHOD
}

\author{
Shunmei Guo ${ }^{1}$, Weixiao Wang ${ }^{1 *}$, Peng Shi ${ }^{1}$ \\ ${ }^{1}$ Department of Railway Vehicle, Hebei Vocational College of Rail Transportation, Shijiazhuang, \\ 052165, Hebei, China \\ *Corresponding: Weixiao Wang \\ Email: wangweixiao72@126.com
}

\begin{abstract}
In the fast-increasing speed of EMUs (Electric Multiple Units), the stability, reliability and smoothness of the EMUs in operation are guaranteed by exploring the rotor vibration model of the traction motor equipment of the EMUs. The finite element model of the rotor is constructed using the finite element algorithm, and the rotor model is used to simulate the rotor of the traction motor according to the radial vibration. The influence of factor changes on the vibration characteristics of the rotor system is discussed. Finally, the radial vibration effect on the rotor under the influence of various factors is explored through simulation. The results show that in the bending mode analysis of the rotor system, the rotor presents four bending modes; in the analysis of the influence factors of the radial vibration of the rotor system, the angle of unbalanced magnetic pull, the angle of rotor gravity, and the angle of rotor bending stiffness are compared. The analysis of the influence of the radial vibration of the rotor shows that the unbalanced magnetic tension increases the amplitude of the rotor and reduces the natural frequency of the radial vibration of the rotor system. The radial dimension of the axis track and the displacement spectrum has no significant difference with or without gravity. When the position of the axis track is relatively static, the offset distance of the rotor centre decreases with the increase of stiffness. When the rotation frequency component is $0.8 \mathrm{k}_{0}$, the amplitude is the largest; in the bending-torsion coupling analysis, the largest amplitude is the torsional vibration of the external torque frequency of the excitation, around 840 . Therefore, it is found that radial load leads to torsional vibration of multiple frequencies in the torsional vibration of the rotor, and torsional load also causes bending torsional vibration of multiple frequencies in the torsional vibration of the rotor, which provides a reference for later vibration analysis of the rotor in the traction motor of EMU.
\end{abstract}

Keywords: Finite Element Method; Electric Multiple Unit; Rotor; Radial Vibration Model; BendingTorsion Coupling.

\section{Introduction}

With the rapid development of China's national economy, there appear a variety of transportation logistics. As one of the main modes of transportation, the railway industry also follows the trend of the development in modern society, entering into a new era, namely "high-speed passenger transport, heavy freight", which reflects the distinctive characteristics of the time $[1,2]$. In the field of railway transportation, traction motor is the core component of mechanical and electrical energy conversion in the mechanical traction transmission system of highspeed locomotives. The safety, reliability and smoothness in the operation of traction motors attract more and more attention. The traction motor is the source that leads to the driving safety risks of the locomotive. And its vibration characteristic is an important basis for motor design, manufacture and fault diagnosis [3]. Therefore, it has great engineering application value to discuss the dynamic characteristics of the traction motor rotor of the high-speed locomotive group from the vibrational system.

In the course of high-speed train operation, phenomena such as speed fluctuation and vibration of various components of the drive device are common, which may cause great traction torque. Both ends of the traction motor rotor are supported by rolling bearings on the motor housing and there is an air gap between the fixed rots. Powered by an inverter, the cross-transition three-phase current enters the stator-winding and generates a rotating magnetic field in the motor air gap, cutting the rotor 
conductor to generate induced electromotive potential and induction current. And then the rotating magnetic fields interact with each other to generate an electromagnetic torque, which eventually drives the rotor drag load to achieve rotation [4]. There are a variety of radial and torsional loads on the traction motor rotors of the locomotive group, which are subjected to a combination of mechanical imbalance, unbalanced magnetic pull, gravity, bearing reaction, drive torque and load torque during operation [5]. The statorbearing-rotor in the traction motor forms a rotor twist-coupled vibration system. Some studies show that when the high-speed train in China is tested on the Great Western Line and the speed changes dramatically, the vibration of the drive device is particularly obvious. If the vibration is more intense than the maximum speed, the increase of vibration amplitude will have a greater impact on the drive device, easily producing the consequences of rising motor and gearbox temperature, cracks in the axle, which is not conducive to long-term safe operation $[6,7]$. The model constructed using finite element method is usually more accurate, and it can respond successfully to the influence caused by many other factors.

Many scholars study the rotor dynamics system. Novotný et al. (2018) proposed an efficient and numerically stable radial sliding floating ring bearing calculation model. Based on the numerical solution of the Reynolds equation and the analytical description of the resulting variables, the model was finally applied to the virtual turbocharger assembled in the multibody system [8]. Bose et al. (2019) modelled material-level matching and temperature distribution using NLTD (Nonlinear Temperature Distribution,) and ETD (Exponential Temperature Distribution), and studied two different FG (Functionally Graded) materials, stainless steel-ZrO $\mathrm{Zr}_{2}$ and stainless steel- $\mathrm{Al}_{2} \mathrm{O}_{3}$ rotor systems. The results showed that different idempotent coefficients, materials and laws of materials affected the natural frequency of rotor systems [9]. Bouzidi et al. (2020) analysed the dynamic characteristics of the functional gradient rotor-blade system using the finite element method, modelled the rotor-blade system using the Euler-Bernoulli beam theory, and finally discussed the effect of power-law distribution on the inherent frequency of the rotor-blade system.

The results showed that the functional gradient material had advantages in the design and concept of a rotor-blade system compared with metal material [10]. Dewi et al. (2020) proposed a scale method for predicting the frequency of free vibration in large rotor systems. The scale factor of FRF (Frequency Response Function) was first inferred and then validated with finite factors and transfer function models. In the end, in the case of a certain damping ratio, the FRF-based framework analysis characteristics were obtained [11].

Through the discussion of previous studies in related fields, it is found that there are more studies on the bending coupling vibration of various rotor systems, but fewer are on rotor bending vibration for motors and the action of radial electromagnetic forces. And there is rare research on the radial vibration law of rotor radial vibrations for traction motors used in locomotive sets. Therefore, by using the finite element algorithm the rotor finite elements model is constructed, and the rotor model is used to simulate the traction motor rotor to detect the radial vibration of the rotor. Finally, the effect of radial vibration on the rotor under the influence of various factors is analysed. It is expected that the study can provide an experimental reference for the operation of the train operation.

\section{The Radial Vibration Model of the Motor Rotor of EMU}

The purpose is to explore the radial vibration characteristics of the traction motor rotor of the EMU (Electric Multiple Unit) under various radial loads. The influence of the main factors of the motor air gap eccentricity on the radial vibration characteristics of the rotor system is analysed. This is the basis for the analysis of the coupled bending and torsion vibration of the traction motor rotor system of the EMU. Then, the finite element method is used to analyse the flexural natural vibration characteristics of the rotor system. Without considering the torsion, the vibration laws and the vibration characteristics of the rotor are discussed under radial loads such as unbalanced magnetic tension, mechanical unbalanced force, and gravity.

The influence of different eccentricities and factors on the radial vibration characteristics of the rotor is expounded as well.

\subsection{Construction of the Finite Element Model of the Motor Rotor System of the EMU}

The structure of the traction motor rotor is simplified. The core is taken as a cylinder, and the effect of the two end rings of the rotor and the holes in the rotor on the quality characteristics of the core are considered. Then the rotor's shaft, the iron core and the guide bar are regarded as a whole, ignoring the assembly relationship between the three. The rotor is supported by two bearings and rotates at a constant speed. A model of the traction motor rotor system is established on the ANSYS $[12,13]$. The unit model used includes the beam unit and the springdamping bearing unit. 
The rotor structure (axis and iron core) is built by the beam unit, and its nodes are on the axis of the rotor. Rotor bearings are simulated by a springdamping bearing unit, in which only their contact stiffness is taken into account without considering the contact damping, and the bearing contact stiffness value is regarded as a constant [14].

It is assumed that the shaft and the iron core have the same density and Poisson's ratio, but the elastic modulus is different. Because the factors, such as the simplification of the iron core, material properties, quality and stiffness distribution, assembly relationship, influence the rotor structure, the equivalent elastic modulus of the iron core is lower than that of the shaft, between the shaft's elastic modulus and the elastic modulus of the bar. The origin of the model's coordinate system is located at the midpoint of the end surface of the rotor output end (left end), and the x-axis points to the inner side of the rotating shaft along the rotor axis. Two kinds of displacement constraints are imposed on all nodes on the rotor axis, namely displacement along the axis (UX) and rotation displacement (ROTX) around the axis (ROTX); the fixed end of the bearing unit is given a full displacement constraint. In this case, the finite element model of the traction motor rotor system of the EMU is established, and the physical shape is shown in Figure 1.

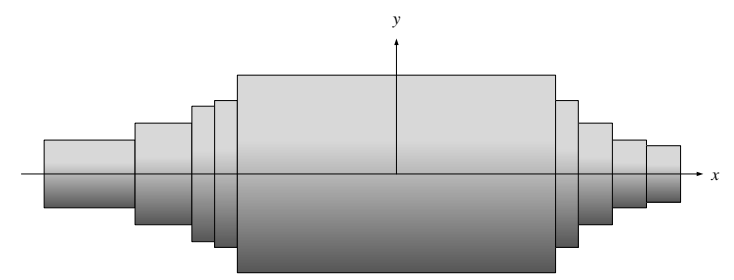

Figure 1: Appearance of the finite element model of the traction motor rotor system

Since the traction motor rotor of the EMU is subjected to radial loads such as gravity, mechanical unbalanced force, and unbalanced magnetic pulling force [15]. In view of the radial vibration of the rotor, the rotor model is used to simulate the traction motor rotor, and the influence of the main factors, such as unbalanced magnetic tension, rotor gravity, initial static eccentricity, mass eccentricity, and rotor bending stiffness, on the vibration characteristics of the rotor system is detailed discussed.

The rotor model (Figure 2) is used to analyse the radial vibration of the rotor of the traction motor of the EMU, which can be used to reveal the basic dynamic characteristics of the rotor. It mainly contains a massless elastic shaft, with its stiffness coefficient $\mathrm{k}$ and bending damping coefficient $\mathrm{c}$. In the centre of the shaft, there is a rigid thin disk ignoring the thickness, its mass is $\mathrm{m}$, the mass eccentricity is a, and the rotation frequency of the disk's rotation around point $O_{1}$ is $\Omega$ (angular velocity is $2 \pi \Omega$ ). Unbalanced magnetic tension, mechanical unbalanced force and gravity all act on the centre $\mathrm{O}_{1}$ of the disc. The differential equation of motion for the centre of the rotor disc is:

$$
\begin{aligned}
& m \ddot{x}+c \dot{x}+k x=m a(2 \pi \Omega)^{2} \\
& \cos (2 \pi \Omega) t+F_{m a g x} \\
& m \ddot{y}+c \dot{y}+k y=m a(2 \pi \Omega)^{2} \\
& \cos (2 \pi \Omega) t+F_{m a g y}-m g
\end{aligned}
$$

$\dot{x}$ and $\dot{y}$ are the first-order derivatives of $\mathrm{x}$ and $\mathrm{y}, \ddot{x}$ and $\ddot{y}$ are the second-order derivatives of $\mathrm{x}$ and $y$ respectively. $g$ represents the acceleration of gravity.

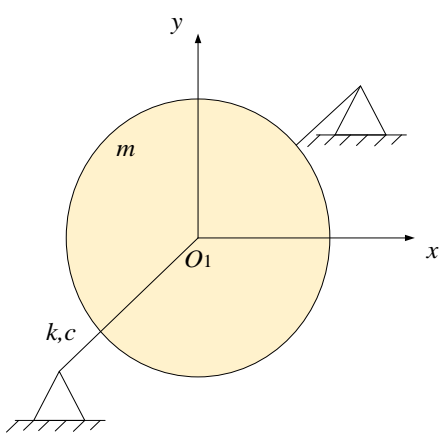

Figure 2: Radial vibration model of traction motor rotor

According to the rotor dynamics theory, when there is no unbalanced magnetic tension, the natural frequency of the rotor radial vibration is as follows:

$$
f_{n}=\frac{\omega_{n}}{2 \pi}=\frac{1}{2 \pi} \sqrt{\frac{k}{m}-\left(\frac{c}{2 m}\right)^{2}}
$$

$C$ represents the damping of the shaft measured in $(\mathrm{N} \cdot \mathrm{s} / \mathrm{m}), k$ refers to the stiffness of the shaft in $(\mathrm{N} / \mathrm{m})$, and $m$ refers to the mass of the disc in $\mathrm{kg}$. In the rotor model, the natural frequency is mainly affected by the mass and stiffness of the rotor and its distribution.

The static eccentricity of the rotor needs to be further considered. When the rotor is at rest, the geometric centre $O_{1}$ of the rotor coincides with the geometric centre $O$ of the stator, without initial static eccentricity; when the rotor rotates, due to the mechanical imbalance force, the geometric centre $O_{1}$ of the rotor moves to $O^{\prime}$, and there is an uneven air gap, resulting in an unbalanced magnetic pull. The vibration of the rotor system with and without unbalanced magnetic tension is analysed.

The rotor of the traction motor is subjected to a constant load of gravity, which causes the bending and deformation of the shaft, affecting the vibration of the rotor system. Besides, gravity causes the rotor air gap to change, thereby affecting the unbalanced 
magnetic pull. Since the dynamic eccentricity of the rotor is considered, the initial static eccentricity is set to zero. Assuming that the mass eccentricity $\mathrm{a}=0.1 \mathrm{~mm}$, the rotor rotates at a constant speed. And the vibration response of the rotor is analysed at different speeds $(\Omega$ is $30 \mathrm{~Hz}, 50 \mathrm{~Hz}$ and $66 \mathrm{~Hz}$ respectively), with or without considering gravity.

Also, the influence of rotor bending stiffness on rotor radial vibration is explored. In the case of rotor dynamic and static compound eccentricity, the rotor gravity is not counted. Suppose the mass eccentricity $a$ is $0.1 \mathrm{~mm}$, the static eccentricity direction is in the positive direction of the x-axis, and the rotor rotates at a constant speed $\Omega=66 \mathrm{~Hz}$. Assuming that the original rotor bending stiffness $\mathrm{k} 0$ is $1.48 \times 108 \mathrm{~N} / \mathrm{m}$, the influence of different rotor bending stiffness $(\mathrm{k})$ on the vibration of the rotor system is obtained.

\subsection{Bending-torsional Coupled Vibration Analysis of EMU Motor Drive System}

During the operation of the EMU, the traction motor rotor system is encountered with the combined action of a variety of radial loads and torsional loads. Thus, radial vibration and torsional vibration occur accordingly, and there is a coupling between the two. The flexural-torsional coupling effect of the rotor makes the vibration of the rotor system more complicated than that of radial vibration or torsional vibration [16, 17]. And the bending and torsional coupled vibration characteristics are studied.

First of all, make the following basic assumptions for the concentrated mass model of the drive system: (1) consider the vibration state of the motor rotor, ignoring the vibration state of the bearing and the motor itself; (2) Neglect the mechanical transmission efficiency and transmission of the drive system power transmission clearance; (3) the elasticity of axles, gears, couplings are not considered; (4) all driving and transmission elements are regarded as concentrated masses. The values of the moment of inertia and torsional stiffness need to convert to the corresponding value of the equivalent system at the same speed, as shown in the following equation:

$$
i=\frac{n^{\prime}}{n}=\frac{\omega^{\prime}}{\omega}
$$

$i$ refers to the gear transmission ratio, and $n, n^{\prime}$ are the speeds of the driven and driving gears respectively. $\omega$ and $\omega^{\prime}$ are the angular speeds of the driven and driving gears respectively. According to the conservation of kinetic energy, the equation is:

$$
J=i^{2} \cdot J^{\prime}
$$

$j$ and $j^{\prime}$ are the moments of inertia of the driving side and the driven side, respectively. According to the conservation of potential energy, the equation is:

$$
K=i^{2} \cdot K^{\prime}
$$

$K$ and $k^{\prime}$ are the torsional stiffness of the driving side and the driven side respectively. The simplified drive system model is shown in Figure 3.

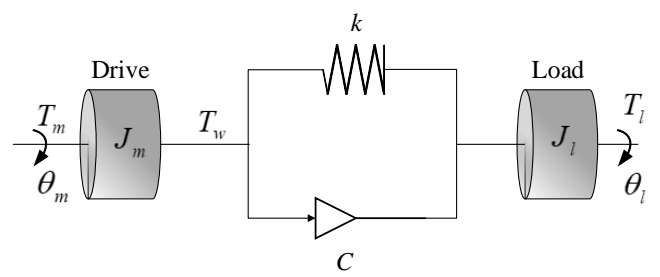

Figure 3: Simplified model of the drive system

In the system, the motor and the load are connected through a drive shaft system, and the drive shaft has a certain stiffness $k$ and damping $C$. When the shaft system is elastically deformed, it will produce torque $T_{w} . T_{w}$ is equivalent to the load torque of the motor, and for the load side, it is equivalent to the driving torque. The system provides electromagnetic torque $T_{m}$ for the drive shaft system. In terms of motor, the torque $T_{m}$ and the drive shaft torque $T_{w}$ act on the motor shaft with a moment of inertia $J_{m}$. On the load, the load has an equivalent moment of inertia $J_{l}$ [18], and the torque $T_{m}$ of the drive shaft system and the load torque $T_{l}$ act together on the load to determine the load speed. According to Hooke's law [19] and mechanical analysis, a set of driving differential equations can be established:

$$
\begin{aligned}
& J_{m} \ddot{\theta}_{m}+C\left(\dot{\theta}_{m}-\dot{\theta}_{l}\right)+k\left(\theta_{m}-\theta_{l}\right)=T_{m} \\
& J_{l} \ddot{\theta}_{l}-C\left(\dot{\theta}_{m}-\dot{\theta}_{l}\right)-k\left(\theta_{m}-\theta_{l}\right)=-T_{l}
\end{aligned}
$$

The Laplace transform of the above differential equations (2-4) is:

$$
\begin{aligned}
& J_{m} \theta_{m} s^{2}+C\left(\theta_{m}-\theta_{l}\right) s \\
& +k\left(\theta_{m}-\theta_{l}\right)=T_{m} \\
& J_{l} \theta_{l} s^{2}-C\left(\theta_{m}-\theta_{l}\right) s \\
& -k\left(\theta_{m}-\theta_{l}\right)=-T_{l} \\
& \omega_{m}=\theta_{m} s, \omega_{l}=\theta_{l} s
\end{aligned}
$$


$\omega_{m}$ and $\omega_{l}$ are the angular velocities of the motor and the load respectively. The transfer functions of motor speed, load speed and motor torque are:

$$
\begin{gathered}
G_{m}(s)=\frac{\omega_{m}(s)}{T_{m}(s)}=\frac{1}{\left(J_{m}+J_{l}\right) s} . \\
\frac{J_{l} s^{2}+C s+k}{J_{m} J_{l}} s^{2}+C s+k \\
G_{m}+J_{l}(s)=\frac{\omega_{l}(s)}{T_{m}(s)}=\frac{1}{\left(J_{m}+J_{l}\right) s} . \\
\frac{C s+k}{\frac{J_{m} J_{l}}{J_{m}+J_{l}} s^{2}+C s+k}
\end{gathered}
$$

In equation (12), the transfer function is composed of two parts: the inertia link and the second-order oscillation link. The left half of the transfer function can be regarded as the sum of the inertia of the motor and the load in the case of a rigid connection, and the right half concentrates all the parameters of the elastic links, taken as the influence of elastic connection on system characteristics [20]. Using the stiffness matrix method [21], the following undamped free torsional vibration equation of the traction motor rotor system is obtained:

$$
J \ddot{\phi}+K_{t} \phi=0
$$

$J$ is the moment of inertia matrix, $K_{t}$ is the torsional stiffness matrix, $\phi$ is the angular displacement vector, and $\ddot{\phi}$ is the second-order derivative of the angular displacement vector. According to vibration mechanics, an undamped system has free vibration in the form of simple harmonic motion, and the solution of equation (14) is:

$$
\phi=A \sin (\omega t+\varphi)
$$

In equation (15), $A$ refers to the vector of the amplitude of the system, and $\omega$ refers to the angular frequency of the undamped free vibration of the system. Putting equation (15) into equation (14), it is obtained:

$$
\left(K_{t}-\omega^{2} J\right) A=0
$$

Therefore, the torsional natural vibration of the computing system is transformed into solving the generalized eigenvalue problem.

\subsection{Simulation}

Using the finite element model of the rotor, the simulation analysis is carried out on the ANSYS platform. In the static coordinate system, the rotor is set to rotate at a constant speed, and the set speed is the rated speed of the traction motor (4100 r/min). Since the gyro effect of the rotor is concerned, the damping method is used to extract the mode shape of the rotor [22], which is analysed.

In the simulation, a certain type of EMU is running at an operating speed $(300 \mathrm{~km} / \mathrm{h})$, and its traction motor is running at a rated speed (4100r/min). The rotor of the traction motor bears the combined action of radial load and torsional load. Set the resistance torque acting on the rotor by a constant torque. A sine wave torque is used to simulate the pulsating driving torque of the traction motor. Its frequency is 6 times the power supply frequency $(840 \mathrm{~Hz})$, and its amplitude is $13 \%$ of the constant resistance torque value. The resistance torque value is the damping load torque value of the traction motor rotor running at the rated speed. In the analysis of the radial vibration model of the EMU motor rotor, the effects of the unbalanced magnetic pull angle, the rotor gravity angle, and the rotor bending stiffness angle on the rotor radial vibration are discussed respectively. And the rotor flexuraltorsional coupled vibration effect under radial and torsional loads is also analysed.

\section{Results and Discussion}

\subsection{Bending Mode Analysis of the Rotor System}

By using the rotor finite element model to rotate at a constant speed, the rotor modal vibration model obtained is shown in Figure 4.
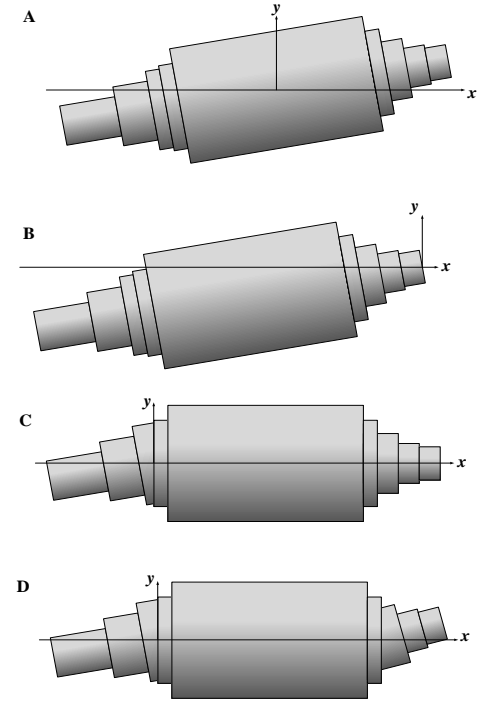

Figure 4: Modal modes of the motor rotor system of the EMU (A. Bending mode 1; B. Bending mode 2; C. Bending mode 3; D. Bending mode 4) 
From the mode shapes of the rotor (Figure 4), the bending vibration mode of the traction motor rotor is similar to the typical beam bending mode. The vibration of bending mode 1 is mainly distributed at the two ends of the rotor. At the two ends, the amplitude is greater, and the vibration in the centre of the rotor is very small. Bending mode 2 shows that the entire rotor is offset from the initial axis, and the amplitude gradually increases along the axis from the input end to the output end of the rotor. The vibration of bending mode 3 is concentrated at the output end of the rotor, and the closer the position is to the end face, the greater the amplitude is. There is almost no vibration at other positions. Bending mode 4 presents the shape of an "S", with larger amplitudes at both ends of the rotor and the bearing position. The bending modes corresponding to 3 and 4 are less likely to be excited in practice.

\subsection{Analysis of Factors Affecting Radial Vibration of the Rotor System}

The effects of the unbalanced magnetic tension angle, the rotor gravity angle, and the rotor bending stiffness angle on the radial vibration of the rotor are discussed respectively, as shown in Figures 5-10.

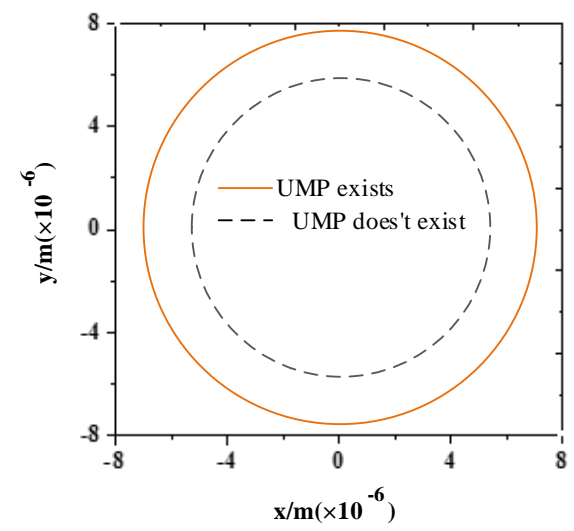

Figure 5: Effect of unbalanced magnetic tension on the trajectory of the rotor axis.

In the presence and absence of unbalanced magnetic tension in the rotor system (Figure 5), the axis orbits are all circular. The radius of the axis track of the rotor is greater when the mechanical unbalanced force and the unbalanced magnetic pull are simultaneously acted on. When only the mechanical unbalanced force acts, the amplitude of the rotor is small. That is to say, the unbalanced magnetic tension increases the amplitude of the rotor.

To analyse the influence of unbalanced magnetic tension on the natural frequency of the radial vibration of the rotor system, the amplitudefrequency characteristics of the rotor shaft displacement are expounded under the condition of no damping $(\mathrm{C}=0)$, and the existence and absence of unbalanced magnetic tension without damping are obtained. The spectrogram of the displacement of the lower rotor axis is as follows:

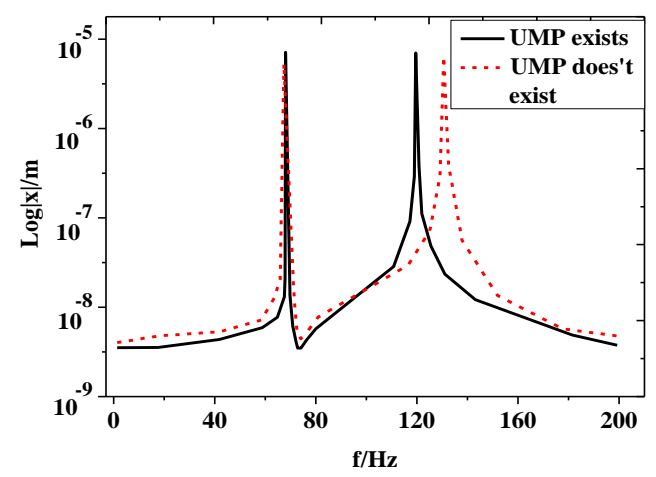

Figure 6: Spectrogram of the displacement of the lower rotor axis

Figure 6 indicates that if the unbalanced magnetic pull does not exist, the rotor shaft displacement includes the rotation frequency component $\Omega(66 \mathrm{~Hz})$ and the natural frequency component $(131 \mathrm{~Hz})$; if the unbalanced magnetic pull exists, the natural frequency component is reduced from the original $131 \mathrm{~Hz}$ to $120 \mathrm{~Hz}$. Therefore, the unbalanced magnetic tension reduces the natural frequency of the radial vibration of the rotor system.
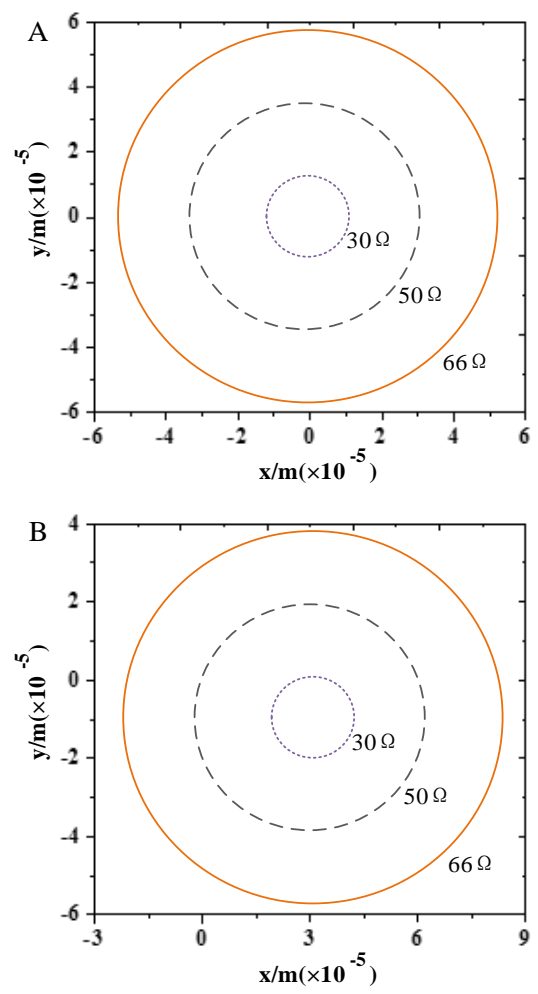

Figure 7: Influence of gravity on the axis trajectory of the static composite eccentric rotor at different speeds (A. with gravity; B. without gravity) 
As shown in Figure 7, when the rotation speed $\Omega=30,50,66 \mathrm{~Hz}$ respectively, the rotor axis trajectory presents an ellipse. As the speed increases, the size of the rotor axis track increases nonlinearly, and the ellipse becomes slightly "flatter" (the ratio of the long axis to the short axis increases). The trajectories of the rotor axis at different speeds form concentric circles, and the geometric centre position of the ellipse does not change with the speed. Without gravity, the long axis of the ellipse trajectory is a straight line in the direction of static eccentricity ( $\mathrm{x}$ axis); the direction of the long axis of the ellipse trajectory is determined by the superposition of the initial static eccentric vector and the eccentric vector caused by gravity. Therefore, there is no significant difference in the radial dimension of the axis orbit with or with gravity. The displacement spectrogram under the influence of gravity is explored further.
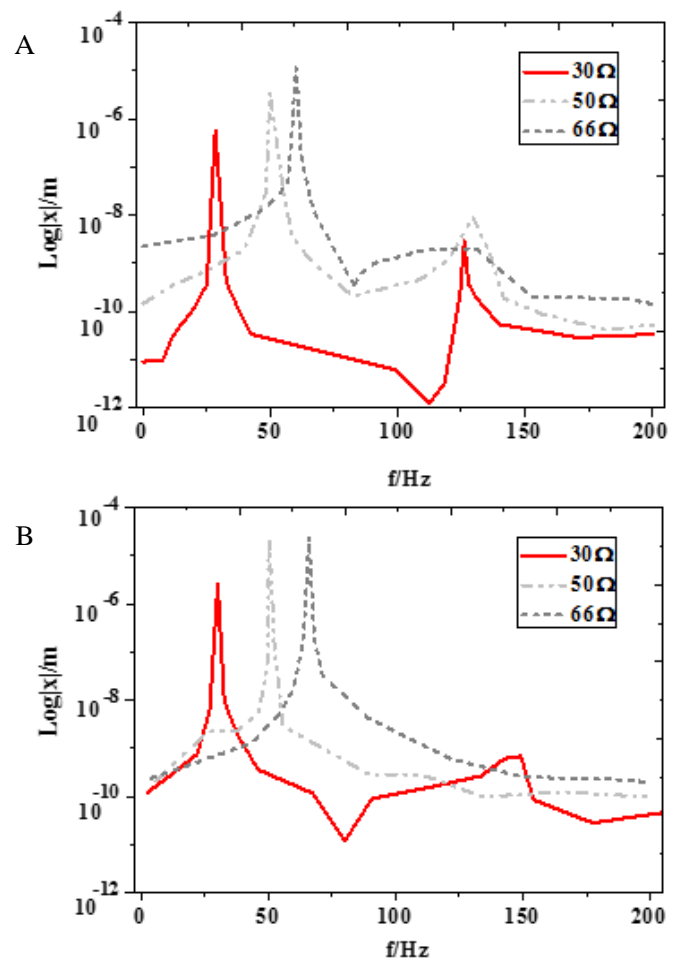

Figure 8: Influence of gravity on the displacement spectrum of a static composite eccentric rotor at different speeds (A. without gravity; $B$. under gravity)

As shown in Figure 8, in the case of rotor dynamic and static composite eccentricity, there is no significant difference in the displacement spectrum of the rotor with gravity or without gravity. The double rotation frequency component appears when the rotation speed $\Omega$ is $30 \mathrm{~Hz}$, and the amplitude of these components increases nonlinearly with the rotation speed. In addition, the shaft displacement vibration also contains its corresponding fixed frequency components $(30 \mathrm{~Hz}, 50 \mathrm{~Hz}$ and $66 \mathrm{~Hz})$, and their amplitudes do not change with the speed.

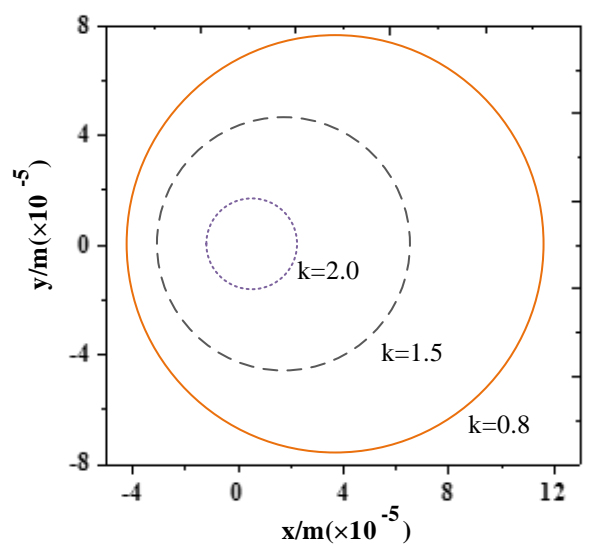

Figure 9: Rotor axis trajectory under different stiffness conditions

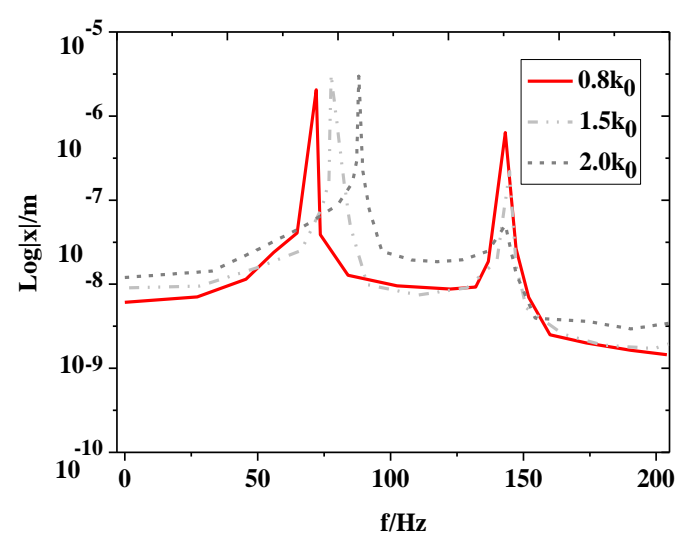

Figure 10: Displacement spectrum of the rotor when the bending stiffness of the rotor is different

In the discussion of the influence of different stiffness conditions on the rotor, the axis trajectory and displacement spectrum are shown in Figure 9 and Figure 10. In Figure 9, it can be found that the trajectories of the rotor axis under different rotor bending stiffness conditions present an ellipse, and are very close to a circle. The major axis of the ellipse is located in the static eccentric direction (x-axis direction). The position of the trajectory is shifted to the static eccentric direction (positive direction of the $\mathrm{x}$-axis). As the stiffness decreases, the amplitude of the rotor increases, and the shape of the ellipse becomes "flat" (the greater the ratio of the long axis to the short axis). And the distance from the centre of the ellipse to the coordinate origin (the centre of the rotor at rest) also increases. In Figure 10, the rotor bending stiffness not only affects the amplitude and natural frequency of the rotor radial vibration, but also places an impact on the azimuth of the axis trajectory distribution. The amplitude of the radial vibration of the rotor decreases with the increase of stiffness. However, the natural frequency increases with the increase of stiffness. Therefore, when the position of the axis track is relatively stationary, the 
offset distance of the rotor centre decreases with the increase of stiffness. Among the vibration components of each frequency under different stiffness conditions, the amplitude of the $0.8 \mathrm{k}_{0}$ rotation frequency component is the largest.

\subsection{Analysis of the Rotor System's Flexural- Torsional Coupled Vibration Effect under Radial and Torsional Loads}

More analysis of the rotor bending-torsional coupled vibration effect under the action of radial and torsional loads is conducted, as shown in Figure 11.

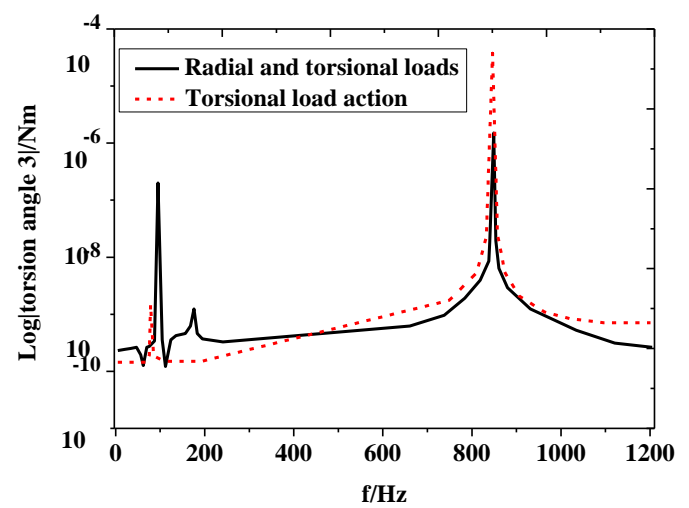

Figure 11: Displacement frequency spectrum of the rotor system under the action of radial and torsional loads

Figure 11 finds that the peak frequency of torsional vibration under the combined action of radial and torsional loads includes rotation frequency $(66 \mathrm{~Hz})$, double rotation frequency (132 $\mathrm{Hz}$ ) and excitation external torque frequency (846 $\mathrm{Hz}$ ). While the rotor system is under the action of torsional load, the torsional vibration of the rotor includes the combination of the rotation frequency and the natural frequency of bending vibration $(139 \pm \Omega)$ and the excitation torque component (849 $\mathrm{Hz}$ ). The torsional vibration of the frequency combination component corresponds to the torsional rigid shape mode of the rotor. And the vibration whose frequency is the combination of the rotation frequency and the natural frequency of the bending vibration is caused by the radial mechanical unbalance force of the rotor. Furthermore, among the torsional vibration components of each frequency, the torsional vibration whose frequency is the frequency of the external torque of the excitation is the largest, followed by the torsional vibration component caused by gravity and unbalanced magnetic tension. Its amplitude is higher than that of other torsional vibration components, more than 2 orders of magnitude.

\section{Conclusion}

The construction of the traction motor rotor system model of the EMU (Electric Multiple Unit) and the bending and torsional vibration law of the rotor under radial and torsional loads are explored. Firstly, the finite element method is used to establish the load model of the rotor, and the traction motor rotor system's flexural natural vibration characteristics are analysed. Secondly, the influence of the changes of the main factors, such as unbalanced magnetic tension, rotor gravity, rotor flexural rigidity and torsional load, on the rotor system vibration characteristics are discussed. It is found that the rotational frequency torsional vibration caused by the rotor gravity and the unbalanced magnetic tension have a significant effect on the torsional vibration of the traction motor rotor, while the torsional load has no obvious effect on the radial vibration of the traction motor rotor, which can provide a reference for future studies in the field. However, the research also has some shortcomings. That is, the unbalanced magnetic tension model is based on the fundamental magnetic potential of the motor stator and rotor, ignoring the harmonic magnetic potential. The influence of harmonic magnetic potential should be considered in the upcoming studies. The suggestions also include: the motor drive torque model can be linked with the traction drive control of the EMU, and the electromagnetic drive torque of the motor is determined by the power supply voltage, current and frequency of the motor.

\section{References}

[1] Yarymbash, D. S., Kotsur, M. I., Yarymbash, S. T., \& Kotsur, I. M. (2017). Features of parameter determination of the induction motor substitution circuit for short-circuit mode. Electrical Engineering and Power Engineering, (1), 24-30.

[2] Nekoubin, A., Soltani, J., \& Dowlatshahi, M. (2020). Comparative Analysis of Three-phase and Five-phase Permanent-magnet Motor Based on Finite Element Method. Journal of Electrical Engineering \& Technology, 15, 1705-1712.

[3] Bouzid, S., Viarouge, P., \& Cros, J. (2020). RealTime Digital Twin of a Wound Rotor Induction Machine Based on Finite Element Method. Energies, 13(20), 5413-5413.

[4] Lin, H., Geng, H., Du, T., Xu, X., Zhang, Y., Cheng, W., \& Yu, L. (2019). Analysis of high-speed permanent magnet synchronous motor rotor supported by air foil bearings. International Journal of Applied Electromagnetics and Mechanics, 59(2), 755-764. 
[5] Vasudeva, C., \& Marwaha, S. (2017). Quasi-Static Field Analysis Of Permanent Magnet Generator Using H-Hierarchical Adaptive Finite Element Method. Journal of Engineering Science and Technology, 12(10), 2613-2627.

[6] Tounsi, S. (2020). Finite element validation of the analytical model of variable reluctance motor. International Journal of Power and Energy Conversion, 11(3), 248-259.

[7] Torrent, M., Perat, J. I., \& Jiménez, J. A. (2018). Permanent magnet synchronous motor with different rotor structures for traction motor in high speed trains. Energies, 11(6), 1549-1549.

[8] Novotný, P., Škara, P., \& Hliník, J. (2018). The effective computational model of the hydrodynamics journal floating ring bearing for simulations of long transient regimes of turbocharger rotor dynamics. International Journal of Mechanical Sciences, 148, 611-619.

[9] Bose, A., \& Sathujoda, P. (2019). Natural frequency analysis of a functionally graded rotor system using three-dimensional finite element method. Vibroengineering PROCEDIA, 29, 70-75.

[10] Bouzidi, I., Hadjoui, A., \& Fellah, A. (2020). Dynamic analysis of functionally graded rotorblade system using the classical version of the finite element method. Mechanics Based Design of Structures and Machines, 1-29.

[11] Dewi, D. K., Abidin, Z., Budiwantoro, B., \& Malta, J. (2020). Dimensional analysis of a rotor system through FRF using transfer function and finite element methods. Journal of Mechanical Science and Technology, 34(5), 1863-1870.

[12] Lu, Z., Wang, X., Hou, L., Chen, Y., \& Li, H. (2018). Dynamic response analysis for the aero-engine dual-rotor-bearing system with flexible coupling misalignment faults. Journal of Vibroengineering, 20(5), 2012-2026.

[13] Yang, W., Liang, M., Wang, L., \& Yuan, H. (2018). Research on unbalance response characteristics of gas turbine blade-disk rotor system. Journal of Vibroengineering, 20(4), 1676-1690.
[14] Liang, X., Ali, M. Z., \& Zhang, H. (2019). Induction motors fault diagnosis using finite element method: a review. IEEE Transactions on Industry Applications, 56(2), 1205-1217.

[15] Wahsh, S., Yassin, A., \& Shazly, J. (2017). Effect of rotor speed on the thermal model of AFIR permanent magnet synchronous motor. studies, 7, 9-9.

[16] Zhang, H., \& Wang, S. (2017). Topology optimization of rotor pole in switched reluctance motor for minimum torque ripple. Electric Power Components and Systems, 45(8), 905-911.

[17] Asadi, F., Abdollahi, S. E., \& Gholamian, S. A. (2020). Rotor Tooth Number Effect on the Performance of a Double Stator Flux Switching Motor with Low-Cost Magnets. Scientific Journal of Applied Electromagnetics, 7(2), 45-52.

[18] Wen, J., Song, C., Fu, Y., \& Guo, P. (2018). Rotor structure optimization of permanent magnet synchronous generator built-in type U. Journal of Jiangsu University (Natural Science Edition), 39(02), 194-198.

[19] Kim, Y. H., \& Lee, J. H. (2018). Calculation on proportion of rotor shape for torque ripple reduction of axially laminated type synchronous reluctance motor. International Journal of Applied Electromagnetics and Mechanics, 56(S1), 153-162.

[20] Zhang, W. D., Luo, Z., Ge, X. B., Zhang, Y. Q., \& Guo, S. W. (2020). Determination method of scaling laws based on least square method and applied to rectangular thin plates and rotorbearing systems. Mechanics Based Design of Structures and Machines, 48(2), 241-265.

[21] Yang, Z., Ding, Q., Sun, X., Ji, J., \& Zhao, Q. (2019). Design and analysis of a novel wound rotor for a bearingless induction motor. International Journal of Electronics, 106(12), 1829-1844.

[22] Li, Z., Chen, Q., Yue, F., \& Wang, Q. (2019). Analysis of the rotor dynamics characteristics of multi-degree-of-freedom permanent magnet synchronous motor. Journal of Low Frequency Noise, Vibration and Active Control, 38(2), 352362. 